\title{
The lesser Pacific striped octopus, Octopus chierchiae: an emerging laboratory model for the study of octopuses
}

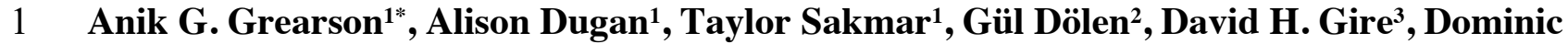 \\ 2 M. Sivitilli ${ }^{3}$, Cristopher M. Niell ${ }^{4}$, Roy L. Caldwell ${ }^{5}$, Z. Yan Wang ${ }^{6 * *}$, Bret Grasse ${ }^{1+*}$ \\ 4 \\ ${ }^{1}$ Marine Resources Center, Marine Biological Laboratory, Woods Hole, Massachusetts, USA \\ ${ }^{2}$ Department of Neuroscience, Johns Hopkins University, Baltimore, Maryland, USA \\ ${ }^{3}$ Department of Psychology, University of Washington, Seattle, Washington, USA \\ ${ }^{4}$ Department of Biology and Institute of Neuroscience, University of Oregon, Eugene, Oregon, \\ USA \\ ${ }^{5}$ Department of Integrative Biology, University of California, Berkeley, California, USA \\ ${ }^{6}$ Department of Ecology and Evolutionary Biology, Princeton University, Princeton, New Jersey, \\ 10 USA
}

11 †These authors share senior authorship

12 *Corresponding authors:

13 agrearson97@gmail.com

14 zywang@princeton.edu

15 bgrasse@mbl.edu

16 Abstract

Cephalopods have the potential to become useful experimental models in various fields of science, particularly in neuroscience, physiology, and behavior. Their complex nervous systems, intricate color- and texture-changing body patterns, and problem-solving abilities have attracted the attention of the biological research community, while the high growth rates and short life cycles of some species render them suitable for laboratory culture. Octopus chierchiae is a small octopus native to the central Pacific coast of North America whose predictable reproduction, short time to maturity, small adult size, and ability to lay multiple egg clutches (iteroparity) make this species ideally suited to laboratory culture. Here we describe novel methods for culture of $O$. chierchiae, with emphasis on enclosure designs, feeding regimes, and breeding management. Our results demonstrate the feasibility of multigenerational culture of $O$. chierchiae. Specifically, $O$. chierchiae bred in the laboratory grows from a 3.5-millimeter mantle length at hatching to an adult mantle length of approximately 20-30 millimeters in 250-300 days, with 14-15\% survivorship to over 400 days of age in first and second generations. $O$. chierchiae sexually matures at around an estimated six months of age and, unlike most octopus species, can lay multiple clutches of eggs, approximately every 30-90 days. Eggs are large and hatchlings emerge as direct developing octopuses. Based on these results, we propose that $O$. chierchiae possesses both the practical and biological features needed for a model octopus that can be cultured repeatedly to address a wide range of fundamental biological questions. 


\section{Introduction}

Cephalopods (octopuses, squid, cuttlefish, and nautiluses) are a diverse and wide-spread class of marine molluscs that have long been useful for scientific research. Studies of their complex nervous systems (Young, 1971), dynamic skin patterns (Hanlon et al., 2011), and arm biomechanics (Gutfreund et al., 2006; Sumbre et al., 2005; Tramacere et al., 2014), have yielded many foundational insights into physiology, developmental biology, and neurobiology (Shigeno and Ragsdale, 2015; Stubbs and Stubbs, 2016; Di Cosmo et al., 2018; Edsinger and Dölen, 2018; Wang and Ragsdale, 2018; Geffeney et al., 2019; Juárez et al., 2019; Maiole et al., 2019; van Giesen et al., 2020; Schnell et al., 2021). Unique amongst coleoid cephalopods, octopuses demonstrate higher-order cognitive capabilities most commonly attributed to vertebrates, including tool use, problem solving, observational learning, and episodic memory (Hochner et al., 2006; Huffard, 2013; Hanlon and Messenger, 2018).

Despite the immense potential for comparative biological research between cephalopods and vertebrates, several biological and technical reasons have hindered the advancement of octopus culture in laboratory settings:

1) Water quality: Cephalopods produce a large amount of nitrogenous waste compared to other marine organisms (Boucher-Rodoni and Mangold, 1995). Octopuses have a rapid metabolism and a high rate of waste production (Hanlon, 1987; O'Dor, 1987; Lee et al., 1995). Changes in water parameters, such as high ammonia or nitrogen levels, can greatly impact octopus development and health (Oestmann et al., 1997; Lee et al., 1998). Maintaining optimal water quality at all times is paramount to the success of octopus culture (Boletzky and Hanlon, 1983; Hanlon and Forsythe, 1985; Vidal and Boletzky, 2014).

2) Diet: Octopuses are active predators and have specific dietary requirements to maintain rapid growth, especially as hatchlings (Lee et al., 1998; Navarro et al., 2014; Vidal et al., 2014); they require a high protein and relatively low high-quality lipid diet (Miliou et al., 2005; Rosas et al., 2013; Vidal et al., 2014).

3) Safe containment: Most octopus species are highly cannibalistic (Ibánez and Keyl, 2010) and solitary as adults; conspecific aggression is very common. Therefore, individual enclosures are required to house animals safely. This increases the space, materials, and amount of seawater necessary for rearing octopuses in the lab. Further, octopuses are notoriously skilled at escaping containment, so the design of octopus enclosures must include sufficient measures to prevent their escape (Wood and Anderson, 2004).

4) Life history attributes: Most cephalopod species are semelparous; they die after one reproductive event (Mangold, 1987; Cortez et al., 1995). For example, females of commonly studied octopus species, including Octopus bimaculoides, Octopus vuglaris, and Octopus maya, lay only one clutch of eggs in their lives. Octopus hatchlings can undergo one of two mechanisms of development: indirect and direct development. Small egg species, such as $O$. vulgaris, undergo indirect development; they lay large numbers of small eggs that develop into planktonic paralarvae before undergoing metamorphosis to achieve the benthic stage (Vidal et al., 2014), conditions which are extremely difficult to replicate in the lab. Large egg species, such as $O$. bimaculoides, undergo direct development and hatchlings emerge as fully developed benthic octopuses, which 
also experience high rates of mortality (Itami et al., 1963; Iglesias et al., 2000; Iglesias et al., 2004; Vaz-Pires et al., 2004; Vidal et al., 2014; Garrido et al., 2018). These natural life history attributes greatly limit octopus reproduction and the rearing of hatchlings in laboratory settings, and multigenerational culture of these species has not yet been achieved (Iglesias et al., 2007).

Here, we overcome these challenges by advancing the laboratory aquaculture of the lesser Pacific striped octopus, Octopus chierchiae (Figure 1). O. chierchiae is native to the central Pacific coast of the Americas (Voss, 1971) and lives in low intertidal zones at water depths up to 40 meters (Rodaniche, 1984; Hofmeister et al., 2011). Several unique biological features make O. chierchiae particularly amenable for laboratory culture and scientific research. As adults, O. chierchiae are very small: the largest $O$. chierchiae adult mantle length previously reported was 25 millimeters (mm) (Rodaniche, 1984). Other octopus study species, such as O. bimaculoides, O. maya, and $O$. vulgaris, can reach a mantle length three to ten times larger than O. chierchiae (Jereb et al., 2014). Unlike most octopus species, $O$. chierchiae is iteroparous. Individuals can undergo multiple rounds of reproduction and lay successive clutches of eggs before death, which is useful for planning and managing the reproductive outputs of a colony of research animals (Rodaniche, 1984; Hofmeister et al., 2011). O. chierchiae is a large egg species and lacks a paralarval phase (Rodaniche, 1984); hatchlings are direct developing and emerge with a highly developed nervous system and innate hunting behaviors (Vidal et al., 2014). Mature males and females are visually and behaviorally sexually-dimorphic: the tip of the third right arm in male $O$. chierchiae lacks suckers and is modified with a hectocotylus, a smooth, hooked organ used to pass spermatophores to the female during mating (Voss, 1968; Rodaniche, 1984; Figure 1B). Males also exhibit a visually striking arm-twirling behavior in which they rapidly shake the tips of their arms (Hofmeister et al., 2011), which here we call "tasseling". In addition, $O$. chierchiae are marked by sharply contrasting black and white striping patterns (Figure 1A), which are unique to each individual and can allow for non-invasive identification (Hofmeister et al., 2011). Thus, culture of $O$. chierchiae requires significantly less physical space to produce many generations of directly developing offspring that can be visually identified, making them particularly advantageous for laboratory study as compared to other octopus species used in research.

Culture of $O$. chierchiae has been attempted multiple times since the 1970's without success. The primary reasons for failure include inadequate diet and nutrition at early life stages, inadequate holding enclosures and seawater systems, and gaps in general knowledge of their biology and behavior (Rodaniche, 1984). Collection of this species has been infrequent and challenging since the 1970 s, so little is known about $O$. chierchiae natural history in the wild. This makes the ongoing culture of this species critical for laboratory use and for direct observation of their behaviors. Multi-generational laboratory culture of octopuses has only been reported in one other species, O. maya (Van Heukelem, 1977). Here, we document the first successful multigenerational culture of $O$. chierchiae at the Marine Biological Laboratory in Woods Hole, MA. Through the creation of new low-cost enclosures using commonly sourced and commercially available materials, an amended diet, and rigorous cleaning and maintenance protocols, we successfully raised $O$. chierchiae in the laboratory for three generations. Octopuses grew from a $3.5 \mathrm{~mm}$ mantle length at hatching to an adult mantle length of approximately $20-30 \mathrm{~mm}$ in 250 300 days, with 14-15\% survivorship to over 400 days of age in first and second generations. We estimate that $O$. chierchiae sexually mature at around six months of age, and can lay multiple clutches of eggs, approximately every 30-90 days. Based on these results, we propose that $O$. 
bioRxiv preprint doi: https://doi.org/10.1101/2021.08.04.455148; this version posted August 6, 2021. The copyright holder for this preprint (which was not certified by peer review) is the author/funder, who has granted bioRxiv a license to display the preprint in perpetuity. It is made available under aCC-BY-NC-ND 4.0 International license.

120 chierchiae possesses both the practical and biological features needed for a model octopus that can 121 be cultured repeatedly to address a wide range of fundamental biological questions.
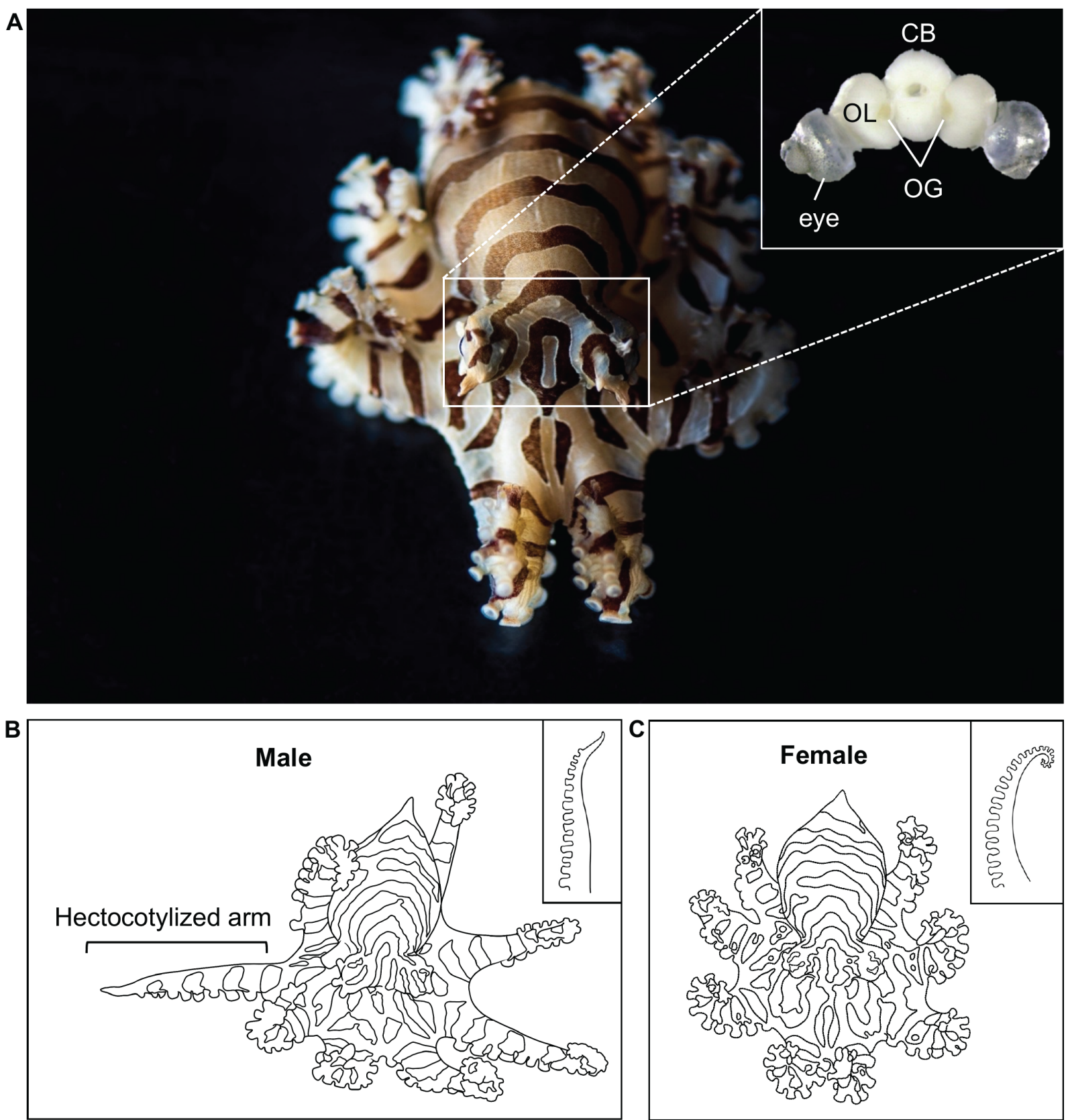

Figure 1. Adult Octopus chierchiae. (A) Dorsolateral view of an adult $O$. chierchiae, an iteroparous species of octopus native to the Pacific coast of North and Central America. Visual stripes are present 7-14 days after hatching and can be used to distinguish individuals. Inset depicts central nervous system with eyes attached. Two large, kidney-shaped optic lobes (OL) flank the central brain mass (CB; supraesophageal and subesophageal masses). The optic glands (OG) sit on top of the optic tract between the OL and the CB. (B) Illustration of a male $O$. chierchiae with the hectotoylized arm extended. Male adult $O$. chierchiae possess a specialized organ on the tip of the third right arm, the hectocotylus (depicted in inset), which has a smooth, sucker-less, hook-like appearance and is used to pass spermatophores to the female during mating. (C) Illustration of a female $O$. chierchiae, lacking a hectocotylized arm. Female adult $O$. chierchiae possess suckers along the full length of all arms (depicted in inset). Image A courtesy of Tim Briggs. 


\section{Methods}

\subsection{Water chemistry}

Water quality was tested weekly, and all water parameters were kept within optimal ranges as outlined in previous reports of cephalopod culture (Hanlon and Forsythe, 1985; Grasse, 2014). pH was tested using an Orion Star A221 meter and maintained between 8.0-8.3 using Two Little Fishes Kalkwasser to raise $\mathrm{pH}$ values when needed. Seawater temperature was tested using an Orion Star A221 meter and maintained between $72^{\circ} \mathrm{F}-76^{\circ} \mathrm{F}\left(22^{\circ} \mathrm{C}-24^{\circ} \mathrm{C}\right)$ using $500 \mathrm{w}$ Finnex immersion heaters. Salinity was kept between 33-35 parts per thousand (ppt), tested using a Hach Hq40d multi meter. Salinity was lowered by adding reverse osmosis (RO)/deionized (DI) water or raised by adding hypersaline Marine Enterprise Crystal Sea Bioassay Laboratory Formula salt mix. Dissolved oxygen was tested using a Hach Hq40d and maintained at $>80 \%$ through water changes and Bubblemac Industry air stones. Ammonia and nitrite levels were measured using a Hach DR3900 spectrophotometer and were maintained at 0 parts per million (ppm) and nitrate levels were kept at $<15 \mathrm{ppm}$, via water changes and water purification methods described below.

\subsection{System design and tray maintenance}

Two types of seawater systems were used during the culture of this species: closed and semi-closed (Figure 2). Both system types produced successful results for keeping and culturing $O$. chierchiae. Closed refers to a system with a reservoir of artificial seawater that recirculates continuously through the appropriate filtration (mechanical, chemical, and biological) and ultraviolet (UV) sterilization. The artificial seawater was made by mixing Marine Enterprise Crystal Sea Bioassay Laboratory Formula with RO/DI water, and 10\% water changes were performed weekly as needed depending on water quality. Due to fluctuations in natural water chemistry in Vineyard Sound throughout the year, closed systems were beneficial in supplying consistent water chemistry and conditions.

Semi-closed seawater systems consisted of filtered seawater from Vineyard Sound, MA, USA with a turnover rate of $200 \%$ per day and the seawater recirculating through the appropriate filtration (mechanical, chemical, and biological) and UV sterilization. Prior to entering the systems, the seawater was filtered via a Stark horizontal sand filter consisting of three grades of Dryden Activated Filter Media ${ }^{\circledR}$ and topped with granulated activated carbon. Seawater was then directed through an 80W Emperor Aquatics SMART UV Sterilizer, 50-micron pleated cartridge filter, and granulated activated carbon cartridge and Seachem Cuprisorb ${ }^{\mathrm{TM}}$ packet.

Both closed and semi-closed systems used aerated, submerged Kaldnes K1 media for biological filtration. Size and wattage of UV sterilizers were dictated by the water volume (100150 gallons) and flow rates of each specific system ( $\sim 90 \mathrm{ml} /$ second in fiberglass trays). Submerged granulated activated carbon was used in each reservoir and replaced monthly. All seawater was mechanically filtered via 50-micron bag filters that were changed weekly. Protein skimmers were used in the reservoirs where appropriate and sized according to each system volume. Protein skimmers were cleaned two to three times weekly, the bag filters once weekly, the cartridge filters every two weeks, and the entire trays once every one to two months. These were scrubbed and/or sprayed clean and rinsed with tap water to remove detritus, soaked in $10 \%$ bleach/water solution, then soaked in a mixture of $10 \%$ sodium thiosulfate (Proline ${ }^{\mathrm{TM}}$ )/ water solution to neutralize the 
bioRxiv preprint doi: https://doi.org/10.1101/2021.08.04.455148; this version posted August 6, 2021. The copyright holder for this preprint (which was not certified by peer review) is the author/funder, who has granted bioRxiv a license to display the preprint in perpetuity. It is made available under aCC-BY-NC-ND 4.0 International license.

163 bleach, and finally rinsed thoroughly with DI water before re-use. All systems were kept on a 12164 hour light/dark cycle.
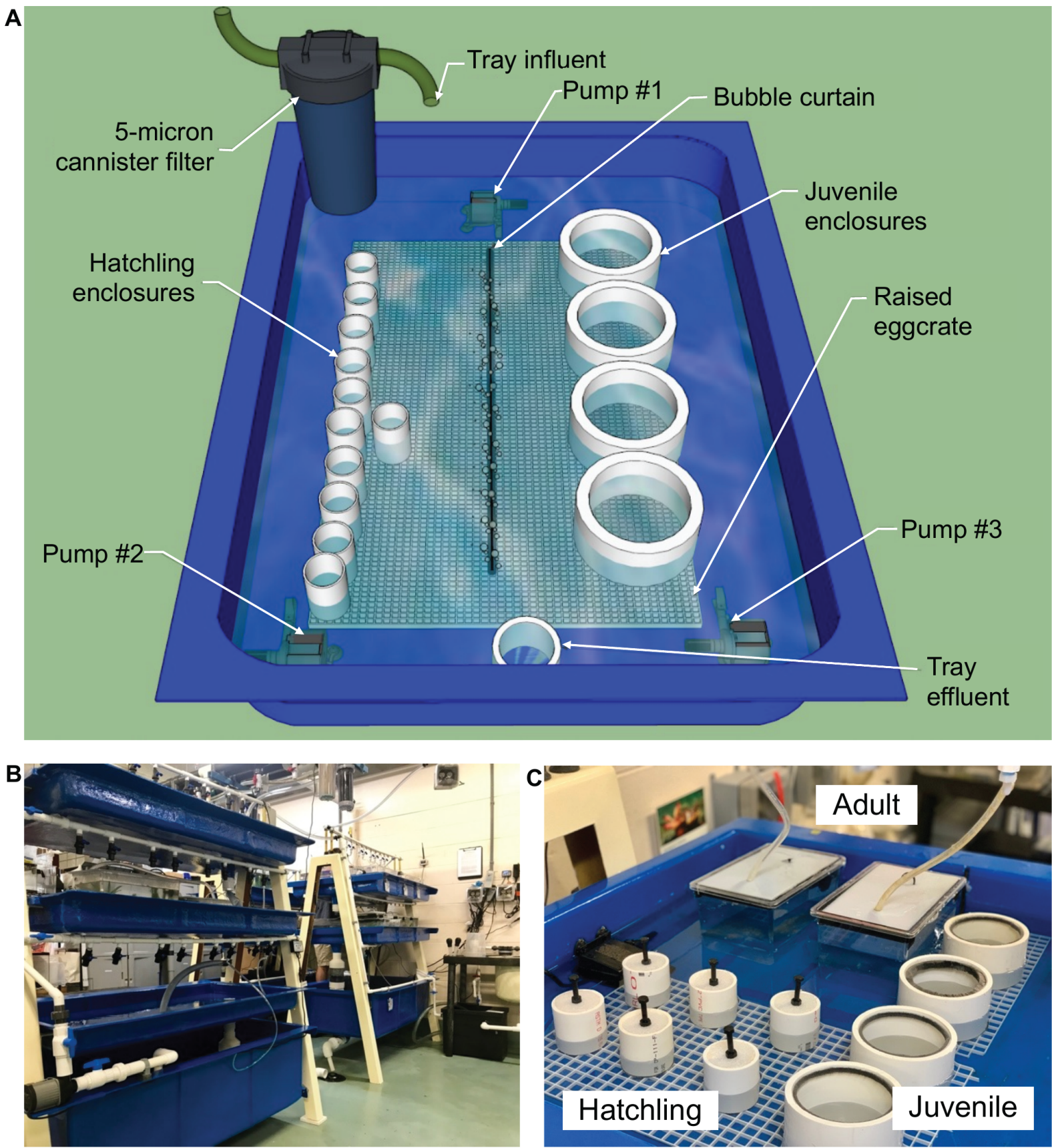

Figure 2. System and enclosure design. (A) Tray design used at the Marine Biological Laboratory. (B) A-frame system design made of fiberglass supports with a large fiberglass reservoir on the bottom and two shallow fiberglass trays above. Water circulates from the reservoir up to the trays via manifolds and discharges back down to the reservoir. Seawater recirculates through the appropriate filtration (mechanical, chemical, and biological) and ultraviolet (UV) sterilization. (C) Adult, juvenile, and hatchling enclosure designs.

Both closed and semi-closed systems utilized custom-built A-frame fiberglass supports with a large fiberglass reservoir on the bottom and two shallow fiberglass trays above (Figure 2B). 
Water circulated from the reservoir up to the trays via manifolds and discharged back down to the reservoir. All individuals were held within the shallow trays of each seawater system, with three to four inches of water depth (Figure 2A). In hatchling and juvenile enclosures (described in Section 2.3), seawater was exchanged through a fine mesh bottom in each enclosure (Figure $2 \mathrm{~B}$ ). Hatchling and juvenile enclosures were elevated off the tray bottom using $1 / 2$-inch by $1 / 2$-inch square-cell polystyrene egg crate tables to support seawater exchange through each enclosure's mesh bottom. Seawater exchange in enclosures was further increased by circulating the water in the tray with small submersible pumps (Rio) in each corner and a bubble curtain running lengthwise down the tray (Figure 2A). Adult enclosures received new seawater directly from valve-controlled supply manifolds on each system (Figure 2B). Displaced effluent water exited through a screened bulkhead back to the fiberglass tray. All seawater in contact with non-native organisms at Marine Biological Laboratory was sterilized with ozonation before returning to the ocean.

\subsection{Enclosure design and maintenance}

Three enclosure designs were used based on the age and size of the octopus (Figure 2C). After hatching, each $O$. chierchiae was housed in a separate enclosure. Once an octopus grew to about half the size of its enclosure (i.e., opposite arm tips reached approximately half of the enclosure diameter), it was transferred to a new enclosure of the next size. The approximate ages at which we moved animals is indicated below. All enclosures were provided with 1-2 dens (see Supplementary Figure S1), and juvenile and adult enclosures also included shells and rocks of varying sizes for enrichment. Dirty enclosures, dens, and materials were scrubbed, cleaned, and rinsed using the cleaning methods described in Section 2.2.

Hatchling enclosures: hatchlings were housed in 1/4-inch polyvinyl chloride (PVC) enclosures with a 125 -micron polyester mesh bottom and were provided $1 / 8$-inch or $1 / 4$-inch barbed fittings as dens. Hatchlings readily escape their enclosures, which can lead to mortality due to desiccation or becoming lost in the system tray. Tight-fitting lids are thus critical to minimize hatchling mortalities due to escape. The lids were removed during feeding, and extra attention was taken to note the location of the octopus during feeds and to ensure the lid was carefully placed back onto the enclosure without crushing the octopus. Hatchlings are very sensitive to changes in water parameters, physical disturbances, or the growth of foreign organisms in their enclosures such as algae, hydroids, or cyanobacteria. To prevent unwanted growth, dirty enclosures, dens, and enrichment materials were replaced with clean ones once every two weeks.

Juvenile enclosures: at approximately three months of age, octopuses were moved to 4inch PVC enclosures with an 840-micron polyester mesh bottom and were provided with $90^{\circ} \mathrm{PVC}$ elbows as dens. To deter octopuses from escaping out of the juvenile enclosures, we attached adhesive Velcro (rough hook side exposed) or adhesive weatherstrip window pile to the top-inner rim of the PVC tube. These materials are difficult for octopus suckers to adhere to and successfully prevented escape. Juvenile enclosures were replaced with clean ones once every three weeks.

Adult enclosures: at approximately six months of age, octopuses were moved to $2.84 \mathrm{~L}$ $(23.1 \times 15.2 \times 15.5 \mathrm{~cm})$ plastic aquaria, each fitted with an opaque High-Density Polyethylene (HDPE) weighted lid, seawater supply line, bulkhead, and filter screen allowing for water to flow directly into and out of the enclosure. A 1250-micron polyester mesh was placed within the filter 
screen of enclosures with egg-brooding females to prevent any potential hatchlings from escaping. Adult enclosures were placed directly in the trays as described in Section 2.2 (Figure 2A) and were provided with various sizes of dens. Adult enclosures were replaced with clean ones once every

213 six to eight weeks.

\subsection{Collection and procurement of wild specimens}

Historically, O. chierchiae have been spotted at several locations along the Pacific coast of map of these locations, see Supplementary Figure S2. In 2018 and 2019, seven adult O. chierchiae (five females, two males) were purchased from a commercial wholesale vendor, Quality Marine (California, USA), to establish cultures. These were wild collected from the Pacific intertidal zones of Nicaragua.

\subsection{Mating trials and monitoring egg development}

To initiate mating, sexually mature female $O$. chierchiae were presented with males. To the best of our knowledge, no previous studies have reported absolute age of sexual maturity in $O$. chierchiae, so indirect measures were used to determine an octopus' sexual maturity. Hofmeister et al. (2011) reported an "arm-twirling" behavior by male $O$. chierchiae during mating. As such, incidence of the arm-twirling behavior, which we call "tasseling", was used as a proxy for sexual maturity in males. In some cases, this behavior was also used to identify the individual as male. Females were deemed to be sexually mature when they reached the age at which males from the same clutch began to display the tasseling behavior, or when they laid their first clutch of eggs (in most cases, this occurred after a mating trial, although some of the wild-collected females laid eggs before being mated in the laboratory) (see Rodaniche (1984)).

Mating trials were performed two to four times per week in one of two methods: 1) introducing the male into the female's enclosure, or 2) introducing the female followed by the male to a new adult enclosure. In both cases, water flow was turned off and all dens and enrichment materials were removed. No noticeable differences in mating behavior were observed with one method over the other and both were used interchangeably. Mating trials were monitored to ensure the male successfully inserted his hectocotylus into the female's mantle opening. Once the male and the female separated, which could take up to an hour, individuals were returned to their home enclosures. Females and males were paired based on age, size, how recently that individual had been mated, and whether that individual had previously sired/laid a viable clutch of eggs. Individuals were mated repeatedly until they started showing signs of senescence, including disorientation, inappetence, discoloration, and abnormal locomotion (Anderson et al., 2002). A mating trial was deemed unsuccessful if a female did not lay a viable clutch of eggs within a month of the mating trial, at which point the female could be mated once again, often with a different male.

After a mating trial, females' dens were visually inspected during daily feeding for presence of eggs. Once a female laid a clutch of eggs, development of the eggs was monitored weekly until hatching and regular enclosure maintenance (described in Section 2.3) was not resumed until after eggs had hatched. The total number of eggs laid was not counted to avoid disturbing incubating females. The number of hatchlings produced per clutch of eggs laid per 
female was counted and the mean calculated for every generation. A one-way analysis of variance (ANOVA) followed by a pairwise Tukey's multiple comparison test were performed to compare the means using GraphPad Prism version 8.0.0 for Windows (GraphPad Software, San Diego,

254 California USA, www.graphpad.com).

Previous attempts at rearing $O$. chierchiae in captivity used live brine shrimp as the main food source, to little success (Rodaniche 1984). We tested a variety of diets for O. chierchiae, including live copepods, frozen shrimp, frozen fish, live grass shrimp, and live crabs. In response to all but the last two food sources, $O$. chierchiae exhibited no interest in eating (i.e., rejected the food item) and showed increased mortality.

In our study, live-collected grass shrimp (Paelomnetes, $\sim 38 \mathrm{~mm}$ from head to tail) from marine estuaries near Woods Hole, MA and crabs (Hemigrapsus sanguineus, 35-40 mm in carapace width) from rocky beaches near Woods Hole, MA were offered to O. chierchiae to consume ad libitum. Hatchlings were fed $1 / 5^{\text {th }}$ of a freshly killed grass shrimp twice daily (morning and afternoon). Individuals in juvenile enclosures were fed $1 / 2$ of a freshly killed grass shrimp once daily in the afternoon and leftover food was removed the next morning. Adult males and non-eggbrooding females were fed a single live crab with the claws removed (to reduce the risk of the prey harming the octopus) once in the afternoon three to four times weekly. Egg-brooding females were hand-fed one whole grass shrimp (Paelomnetes) three to four times weekly. Any leftover food, dead or alive, was removed at the subsequent feeding to minimize waste buildup.

\subsection{Measuring mantle length}

To quantify growth in $O$. chierchiae, we measured mantle length (tip of mantle to midpoint

\subsection{Recording mortalities and survival analysis} between the eyes) of up to five hatchlings per clutch every seven days from hatching until death or the end of the study (see below). Mantle length was measured by photographing the octopus in a clear Pyrex petri dish filled with filtered seawater resting atop a flat six-inch ruler. To minimize stress, we tried to take the photo within a minute of moving the octopus to the dish. We collected data from a total of 66 individual octopuses from the first and second generations. Because few third-generation hatchlings were available, they were excluded from this analysis to reduce the risk of stress caused by increased handling. Images were imported to ImageJ for calibration and mantle measurement. Pooled averages of mantle length were taken at seven-day increments (i.e., age 0-7 days, 7-14 days, 14-21 days, and so on). In early 2020, the COVID-19 pandemic impeded the collection of growth data, and weekly measurements were terminated. At this point in time, an additional 40 adult octopuses (i.e., > 280 days old) were randomly selected for mantle length measurement.

Cause of mortality and date were recorded at time of death. Natural deaths were defined as any mortality not caused by direct human interference or error and included death due to old age or any unknown health-related issues. Other non-natural causes of death included being crushed under enclosure lids (this only occurred with the smallest hatchlings), escape from enclosures, euthanasia with $2-5 \%$ ethanol after observing signs of senescence or compromised health, use in 
experimental diets or enclosures, stress caused by external factors (such as poor water quality), system problems, or other unknown causes (i.e., cause of death was not recorded at time of mortality). Available mortality data was pooled, grouped by generation, and used to plot a survival curve of the population by generation. Mean survival in days was calculated for each generation and a one-way ANOVA followed by a pairwise Tukey's multiple comparison test were performed to compare the means using GraphPad Prism version 8.0.0 for Windows (GraphPad Software, San Diego, California USA, www.graphpad.com). The survival analysis was performed using mortality data from a total of nine first-generation clutches, 15 second-generation clutches, and one third-generation clutch. Individuals whose mortality data was lost or otherwise unavailable $(n=28)$ were not included in these analyses.

\section{Results}

\subsection{Life history of O. chierchiae in laboratory culture}

We cultured three consecutive generations of $O$. chierchiae under laboratory conditions from 2018-2020. From the original seven wild collected adults, a total of nine first-generation clutches, 15 second-generation clutches, and one third-generation clutches were raised to adulthood. These culture efforts produced a total of 771 octopuses: 350 first-generation, 396 second-generation, and 25 third-generation octopuses (Figure 3A; Figure 4D). The overwhelming majority of lab-cultured individuals exhibited normal physical features, with the notable exception of an octopus with 16 arms from a third-generation clutch, which was found dead in its enclosure at four days of age.

Octopuses were moved to juvenile and adult enclosures when they outgrew the size constraints of their given enclosure (i.e., the distance between opposite arm tips reached approximately half of the enclosure diameter). 162 individuals were moved to 4-inch PVC juvenile enclosures at a mean age of 94 days (SEM: 1.8) and 83 individuals were moved to $2.84 \mathrm{~L}$ plastic aquaria adult enclosures at a mean age of 211 days (SEM: 3.3) (Table 1).

Both males and females exhibited typical signs of octopus senescence (Anderson et al., 2002) after reaching ages of over a year and a half. These behaviors sometimes included disorientation, inappetence, discoloration, and abnormal locomotion (Supplementary Figure S3). No individuals reproduced after onset of senescence, although senescence did not appear to be triggered by reproduction, as it is in other octopus species (Anderson et al., 2002; Di Cristo, 2013; Wang and Ragsdale, 2018). 
A total of ten males were recorded exhibiting the tasseling behavior (see Supplementary Video 1) in their home enclosures (Table 2), which was used as an indication that the male was sexually mature, at a mean age of 176 days (SEM: 8.60). The number of males tasseling was likely much higher as it only began to be recorded in the last year of the study.

We conducted a total of 88 mating trials and 22 octopuses (15 females and 7 males) reproduced. Typically, the female initiated mating by slowly approached the male, who was often exhibiting the tasseling display. This was followed by the male pouncing on the female, grasping her by the mantle from the posterior end, and displaying a pale coloration while the female maintained her dark, banded coloration (Figure 4A; for videos of mating trials, see Supplementary Videos 2 and 3). Beak-to-beak mating, a behavior previously reported in LPSO (Caldwell et al., 2015) and in $O$. chierchiae (Hofmeister et al., 2011), was observed in rare instances and did not lead to egg-laying. Successful mating occurred when the male inserted his hectocotylus into the female's mantle and delivered spermatophores (Figure 4B-4C), which was visually confirmed in $38 / 88$ mating trials. Occasionally, a female would eject a spermatophore during or after mating. The duration of time between placing both octopuses in the enclosure to their separation after mating was recorded for 43 mating trials, with a mean duration of 56.6 minutes (SEM: 3.79) but ranged from 15 minutes to over an hour.

\section{A}
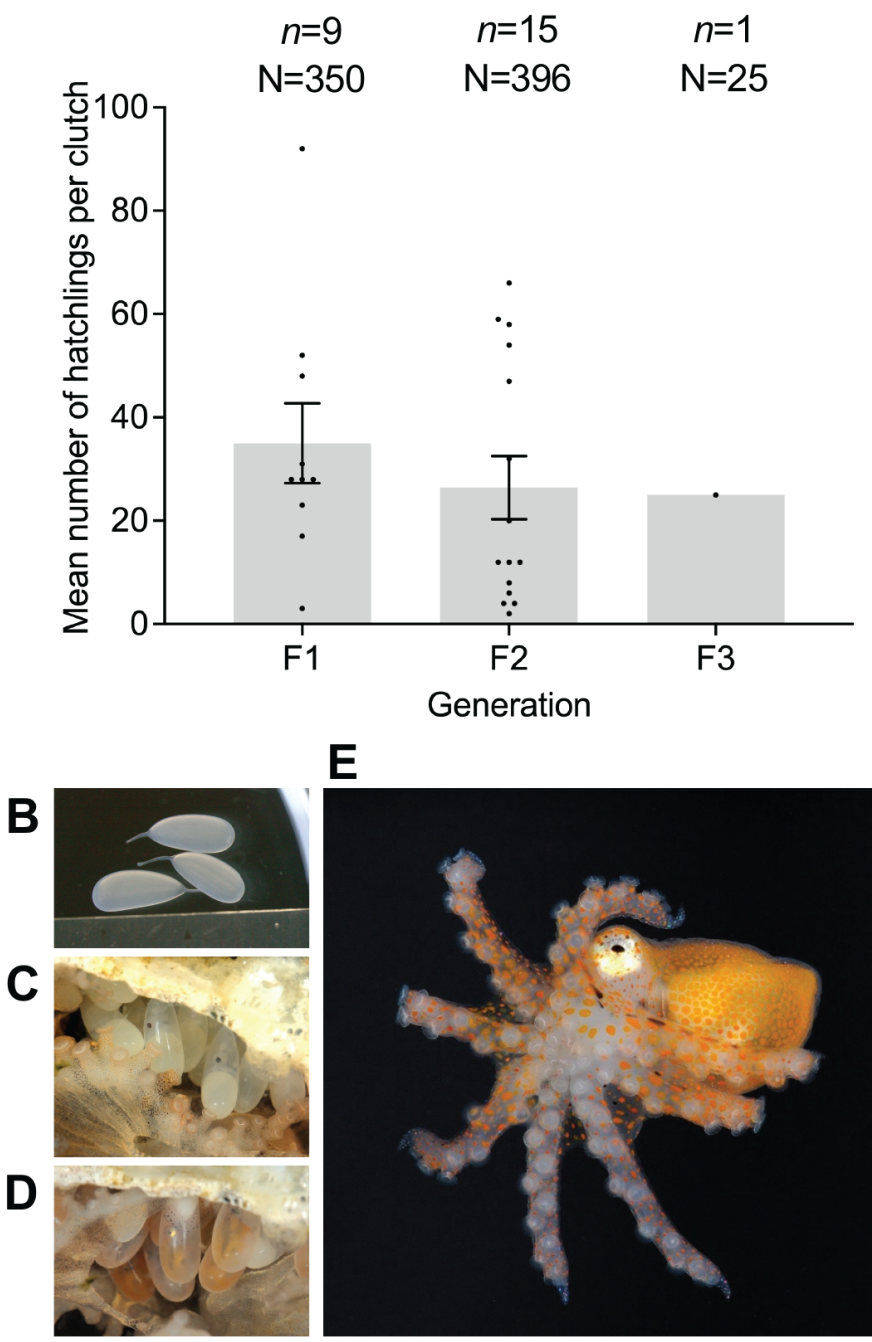

E

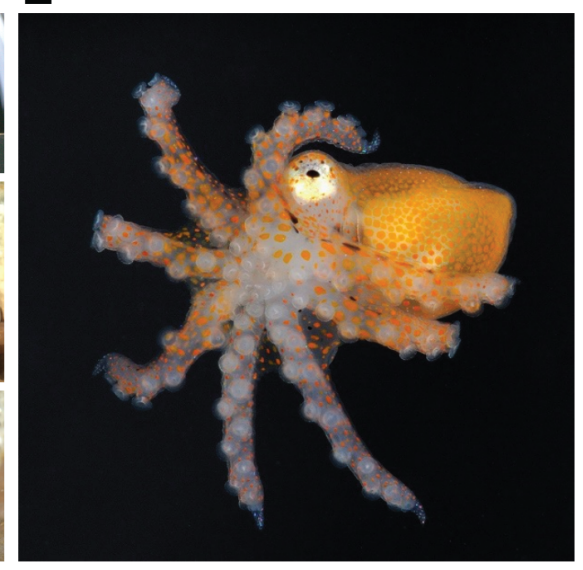

Figure 3. 0 . chierchiae eggs and hatchlings. (A) Mean ( \pm SEM) hatchlings per clutch by generation. A one-way analysis of variance revealed no significant difference between the means of first and second generations $(p>0.05)$. The number of hatchlings for the one third-generation clutch is reported. (B) Translucent, freshly-laid eggs. (C) Eggs with visible eyespots and yolk sac at approximately 17 days post-laying. (D) Eggs with visible chromatophores at approximately 30 days post-laying. $(E) O$. chierchiae hatchling with bright orange pigmentation; $F 1=$ first generation; $F 2=$ second generation; $F 3=$ third generation; $n=$ number of clutches; $N=$ total number of hatchlings; SEM=standard error of the mean. 
A

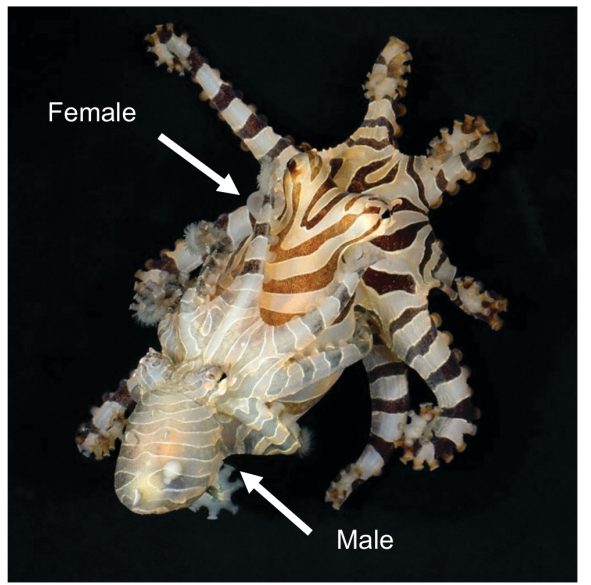

B

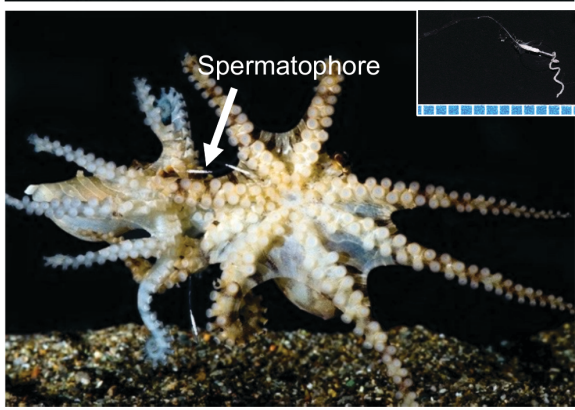

C

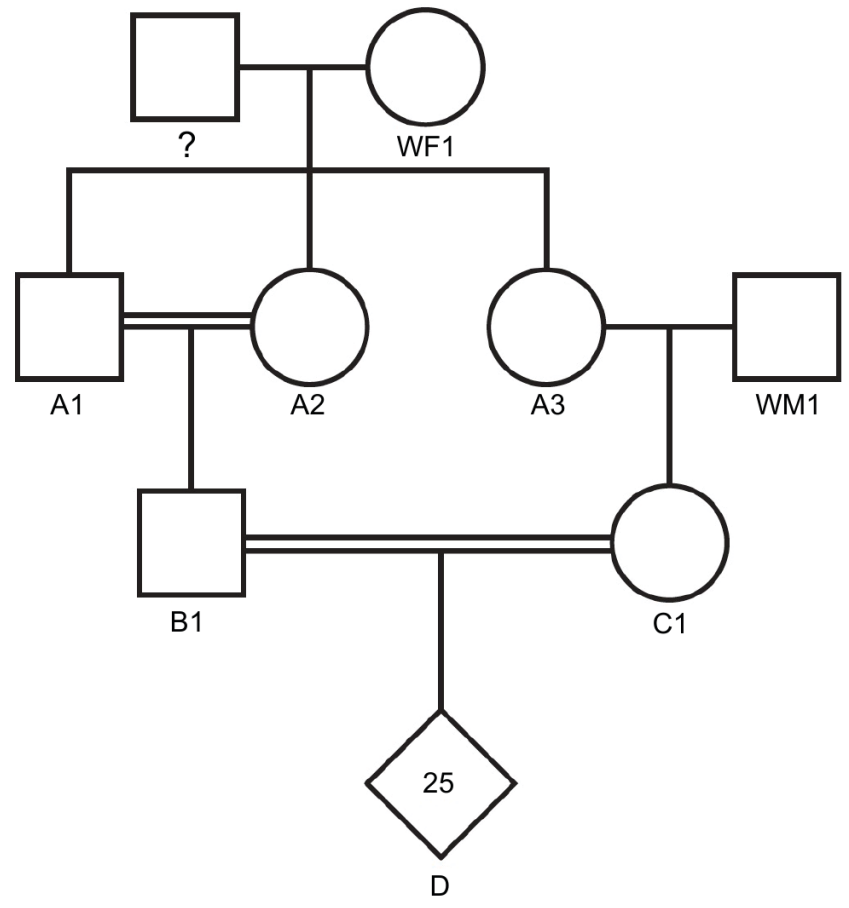

Figure 4. O. chierchiae mating and reproduction. (A) Male (smaller octopus with pale coloration) and female (larger octopus with dark banded coloration) mating (dorsolateral view). The male inserts the tip of his third right arm, called the hectocotylus, into the female's mantle opening to deliver spermatophores.

(B) Visible spermatophores during mating. Inset depicts a spermatophore (scale: millimeters). (C) Pedigree showing parental lineage of a third-generation clutch. Squares represent males, circles represent females, diamonds represent clutches, double solid lines highlight inbred pairs. Female WF1 was a wild-collected female. She had mated previously with unknown partner(s) and produced Clutch $A$ upon arrival in the lab. Two offspring from Clutch A ( 1 1 and A2) were bred together and another offspring from Clutch A (A3) was outbred with a wild-collected male (WM1) to produce two second generation clutches. Two individuals from these second-generation clutches (B1 and C1) mated to produce a thirdgeneration clutch (D) with 25 hatchlings. Note:for clarity, non-reproductive offspring of the first- and second-generation clutches are not represented in this pedigree.

Females laid eggs in their dens between 14-30 days after successful mating. Before laying a clutch of eggs, a female's mantle would swell and, in some cases, eggs could be seen through the partially translucent mantle epidermis by visual inspection. 31 females laid their first clutch of eggs at a mean age of 241 days (SEM: 4.59), which was used to estimate approximate age at sexual maturity in females (Table 2). Some females laid eggs before exposure to a male; these eggs were unfertilized and non-viable. A few females were discovered with mature yet unfertilized eggs in their mantle after death at as early as 134 days of age. Eight females raised in the lab laid multiple clutches; four of them were wild-collected and four were from the first generation. In most of these cases, each clutch was the result of a separate mating trial event. Five of these females laid two clutches of eggs and the other three females laid three clutches of eggs. The duration of time between laying subsequent clutches of eggs varied between 30 to 90 days. In one instance, a firstgeneration female laid two consecutive clutches of eggs after a single mating event, separated by 82 days. Several of the wild females laid a clutch of eggs before having been mated in the 
laboratory. One of these females laid two clutches of eggs without ever being introduced to a male in the laboratory, separated by 66 days. For full data on reproductive mating pairs, see Supplementary Table S1. These observations align with similar ones reported by Rodaniche (1984), where a single female $O$. chierchiae mated twice and laid three viable clutches of eggs, the last of which was laid 83 days after mating.

While brooding, females remained in their dens and positioned themselves below or next to the eggs. Females continued to feed on the shrimp provided to them while brooding, a behavior that has been previously reported in O. chierchiae (Rodaniche, 1984), and evocative of the first stages of maternal care in O. bimaculoides (Wang and Ragsdale 2018). Eggs were approximately $6.20 \mathrm{~mm}$ in length and were white/translucent in coloration (Figure 3B). Egg development progressed in a similar manner to that of LPSO (Caldwell et al., 2015). At approximately 17 days post-laying, a yolk sac and eyespots could be seen developing in the embryo as two dark spots near the center of the egg (Figure 3C). At approximately 30 days post-laying, bright orange chromatophores could be seen in the developing embryos (Figure 3D). Hatchling octopuses, typically bright orange in coloration (Figure 3E), began emerging from eggs between 40-50 days after laying. The mean number of hatchlings that emerged per clutch was 35.0 (SEM: 7.7) for firstgeneration clutches $(n=9), 26.4$ (SEM: 6.1$)$ for second-generation clutches $(n=15)$, and the total hatchlings for the third-generation clutch was 25 (Figure 3A). A one-way ANOVA and Tukey's multiple comparisons test revealed that there was no significant difference between the means for first and second generations $(p>0.05)$.

Occasionally, females laid non-viable eggs or discarded eggs from their den while

\subsection{Growth}

Hatchlings were bright orange (Figure 3E) and stripes began to be visible after brooding, usually fewer than ten eggs. Eggs discarded before embryonic chromatophores were visible did not hatch, while most eggs discarded after formation of embryonic chromatophores hatched if they were stored in a 1 $\frac{1}{2}$ inch PVC enclosure after being discarded. In four instances, brooding females discarded between 10-20 eggs, and the resulting clutch yielded fewer than five hatchlings. Of these, two of the clutches were the second laid by a female while the other two were laid by one-year-old females from the same first-generation clutch.

Five sexually mature males were mated several times without any observed negative effects to their health. One male in the first generation that survived to 402 days of age was mated eight times (with five different females) and sired eight clutches of eggs, producing a total of 214 viable hatchlings (Supplementary Table S1). Three of these females were siblings from the same clutch of eggs as the male. approximately 7-14 days. Hatchlings were benthic and direct developing with a mean mantle length of $3.5 \mathrm{~mm}$ (SEM: 0.07; $n=27$ ) during the first week of life (Figure 5). Rodaniche (1984) reported a similar mantle length in laboratory-raised $O$. chierchiae hatchlings, but due to lack of appropriate food, growth remained static after two weeks, and mortality increased. On a diet of Palaemonetes shrimp and $H$. sanguineus crabs, preliminary observations in this study suggest that mantle length growth is linear from birth until approximately 150-200 days of age, after which it becomes asymptotic (Figure 5). Variability in average mantle length increased dramatically after $\sim 180$ days post-hatch, as many individuals in the growth group died before reaching the end of the 
study and sample size decreased (Figure 5, Supplementary Figure S4). Based on the data from 40 randomly sampled adults between 280 and 800 days of age, average mantle length did not increase with age after 280 days post hatch (Figure 5). The maximum mantle length recorded was $40 \mathrm{~mm}$ in two individuals: one at 550 days post hatch and the other at 799 days post hatch, both of which were from the group of randomly sampled adults.

\subsection{Survival}

Across all three generations, mortality was highest during the first 30-60 days post-hatch. The largest drop in survival occurred in the first five days post-hatch in the third generation (Figure 6A). The mean survival for first, second, and third generations was 128.7 days (SEM: 9.9), 133.3 days (SEM: 8.5), and 25.4 (SEM: 13.7) respectively (Figure 6B). Pair-wise multiple comparisons revealed that mean survival in the third generation was significantly lower than in first and second generations $(p \leq 0.05$.) and there was no significant difference between survival in first and second generations (Figure 6B).
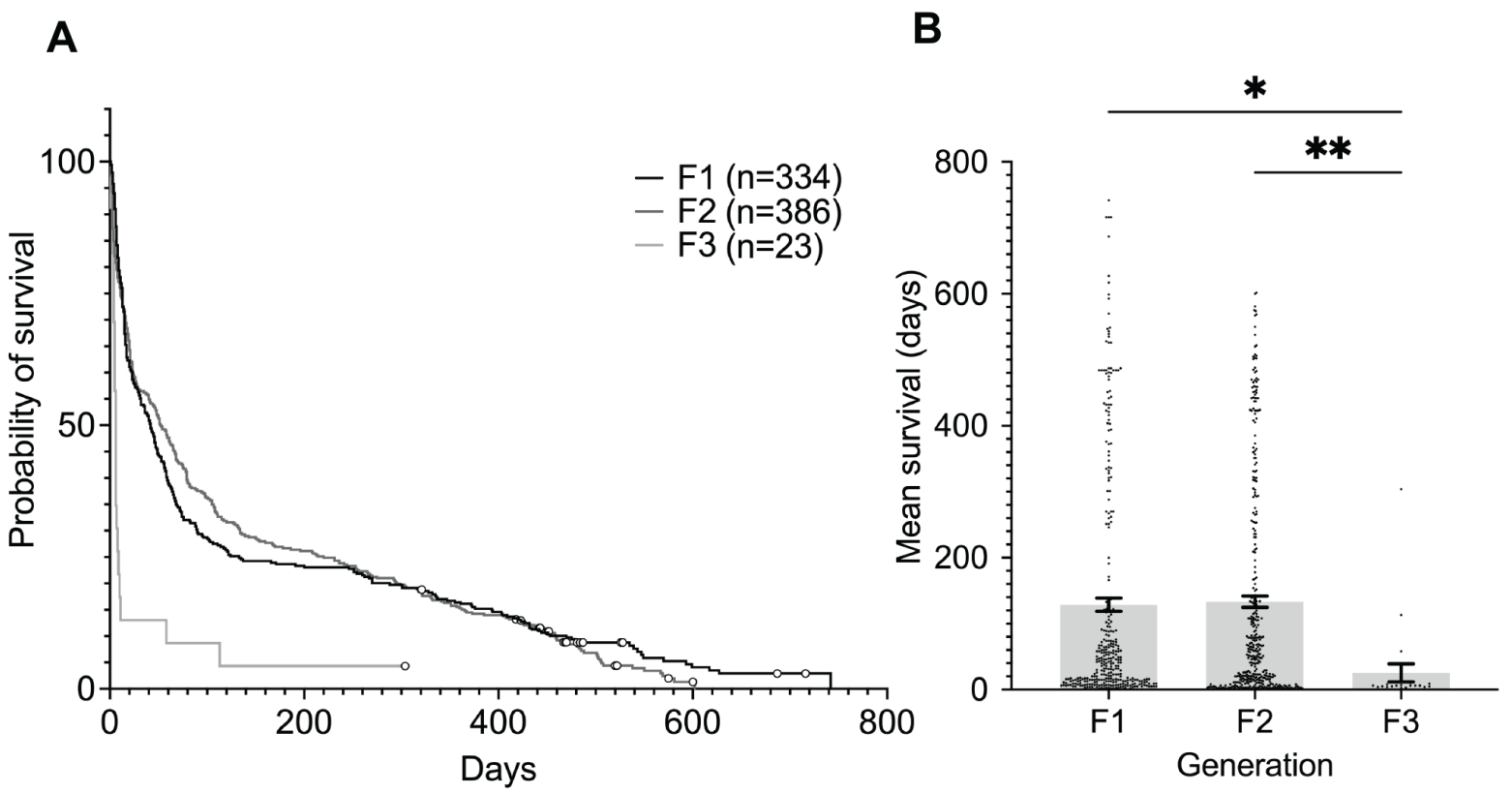

Figure 6. 0 . chierchiae survival by generation. Mortality data was pooled and grouped by generation. Individuals surviving to the end of the study were treated as censored observations, represented by circles. (A) Survival curve by generation. (B) Mean survival ( \pm SEM) in days by generation. A one-way analysis of variance followed by Tukey's multiple comparison test revealed that mean survival in the first and second gener ations was significantly higher than in the third generation. F1=first generation; F2=second generation; F3=third generation; $n=$ number of individuals; $S E M=$ standard error of the mean; ${ }^{*}=$ statistically significant at $p \leq$ $0.05 ;{ }^{* *}=$ statistically significant at $\mathrm{p} \leq 0.005$.

A total of $50(15.0 \%)$ and $54(14.0 \%)$ individuals survived to 400 days or older in the firstand second-generation clutches, respectively. Of these, $11(3.3 \%)$ survived to $>500$ days of age and three $(0.9 \%)$ to $>600$ days of age in the first generation, while $13(3.4 \%)$ survived to $>500$ days of age and one $(0.3 \%)$ to $>600$ days of age in the second generation. A single individual from 
see Supplementary Figure S5. The oldest $O$. chierchiae we recorded in this study was a firstgeneration individual that survived to 742 days of age.

A total of 315,367 , and 22 mortalities were recorded for first, second, and third generations, respectively. Across all three generations, the largest proportion of mortalities were natural deaths: $54.9 \%, 76.6 \%$, and $100 \%$ for first, second, and third generations, respectively (Table 3). The proportion of mortalities due to human error was much higher in the first generation compared to subsequent generations (Table 3).

\section{Discussion}

Octopuses offer a unique and exceptional opportunity to compare complex nervous systems, behaviors, and development across evolutionary distant and anatomically divergent invertebrate and vertebrate model organisms. Studying octopuses from wild-collected specimens, however, restricts the scope of our understanding. New aquaculture methods are needed to rear octopuses in the laboratory. Here, we leveraged the small size and unique life cycle of $O$. chierchiae to establish the first multi-generational laboratory culture of the species. Starting with seven wild-collected individuals, we have been able to successfully rear $O$. chierchiae up to the third generation in large enough numbers to maintain a population spanning all life stages for over two years. All the data presented in this paper represents $O$. chierchiae behavior and life history of laboratory-bred populations. This study represents a significant advance for establishing these animals as a model system for biomedical research.

\subsection{Size and growth considerations}

Given their small body size, $O$. chierchiae require significantly less physical space to house compared to other octopus species. The maximum recorded mantle length of $O$. chierchiae in culture to date $(40 \mathrm{~mm})$ is dramatically smaller than other popular octopus model organisms, such as $O$. bimaculoides, $O$. maya, and $O$. vulgaris, which can reach sizes of up to $85 \mathrm{~mm}, 120 \mathrm{~mm}$, and $250 \mathrm{~mm}$ in mantle length, respectively (Jereb et al., 2014). These species require much larger aquaria and occupy more space on a seawater system and physical space in a building (Wood et al., 2004), while $O$. chierchiae can be held in much smaller tanks. Previous studies have housed individual $O$. bimaculoides in $76 \mathrm{~L}$ tanks (Sinn et al., 2001) and O. vulgaris in $450 \mathrm{~L}$ tanks (Garcia and Valverde, 2006) while $O$. chierchiae can be housed in $2.84 \mathrm{~L}$ tanks. Based on reported adult enclosure sizes, 20 adults of the $O$. chierchiae can be held in a total of $56.8 \mathrm{~L}$ of seawater where O. bimaculoides would require $1520 \mathrm{~L}$ (Sinn et al., 2001) and O. vulgaris would require $9000 \mathrm{~L}$ of total seawater (Garcia and Valverde, 2006). Larger species of octopus also require more food and consequently produce more nitrogenous wastes (Boucher-Rodoni and Mangold, 1995; Oestmann et al., 1997; Lee et al., 1998). Culturing smaller octopuses like O. chierchiae thus reduces the biological load per individual on the seawater system, allowing them to be reared in closed seawater systems (Section 2.2), which are beneficial in maintaining consistent water chemistry and conditions when natural water chemistry in open seawater systems fluctuates.

O. chierchiae hatchlings and juveniles appear to display linear growth during the first 150200 days of life (Figure 5). Based on the data from 40 randomly sampled adults between 280 to 800 days of age, average mantle length did not appear to increase with age after 280 days posthatch (Figure 5). These results suggest that growth rates become asymptotic in adulthood, although 
this may be because diet was not increased during adulthood. Similarly, increasing temperature does not appear to increase growth rates past 6.5 months of age in $O$. bimaculoides (Forsythe and Hanlon, 1988). Average mantle length of adult $O$. chierchiae ranged from approximately 18-25 $\mathrm{mm}$ (Figure 5), and the largest mantle length observed was $40 \mathrm{~mm}$. Growth rate and lifespan are known to be influenced by genetics and environmental factors in cephalopods. Higher temperatures influence egg development, accelerate growth rate early in life, reduce age at reproductive maturity, and shorten lifespan (Mangold and Boletzky, 1973; Forsythe and Hanlon, 1988; Forsythe et al., 1994; Forsythe et al., 2002 Vidal et al., 2002; Grigoriou and Richardson, 2008). Diet is known to increase the growth rate and size of several cultured octopus species (García and Valverde, 2006; Domingues et al., 2007; Rosas et al., 2007; Pham and Isidro, 2009; Prato et al., 2010; Baeza-Rojano et al., 2013). Future studies should investigate the effects of temperature and diet on $O$. chierchiae growth rates, reproduction, and lifespan.

\subsection{Survival and lifespan}

The mortalities that occurred in culture in this study have been largely due to natural causes while a minimal amount was due to human-related interactions (e.g., crushed under lids, experimental diets, direct handling) (Table 2). Reasons for natural death may include old age or other unknown health issues. Due to their low tolerance to ammonia $\left(\mathrm{NH}_{3}\right)$ and nitrite $\left(\mathrm{NO}_{2}\right)$, sources of nitrogenous waste in seawater systems should be removed as soon as possible (Oestmann et al., 1997; Lee et al., 1998). Rigorous water-quality management, frequent water changes, and regular maintenance of enclosures and seawater systems is critical for $O$. chierchiae culture. Frequent interactions from feeding, cleaning enclosures, and morphometric measurements may also be a source of stress if the octopuses are not handled gently. Natural deaths can be reduced through frequent water-quality checks combined with regular feeding and cleaning schedules, while minimizing the frequency of abrasive interactions with the octopuses. Over time, culture techniques of $O$. chierchiae at the Marine Biological Laboratory have greatly improved with continuous iterations of enclosure designs, feeding regimens, and maintenance techniques, along with rigorous training and attention to detail when working with hatchlings. This likely accounts for the decrease in "human-related" causes of death, such as human error, desiccation, and equipment malfunctions with each subsequent generation (Table 2).

In our study, mortality was highest in the first 30 days post-hatch across all generations, but cultured hatchlings regularly survived past 100 days (Figure 6), after which mortality decreased as they aged. Our data suggest that once $O$. chierchiae grow past a highly sensitive hatchling stage, they will be able to survive to sexual maturity. Our results are consistent with the low survival rate of paralarval octopus hatchlings in the wild (Laptikhovsky, 1998; Rocha et al., 2001) and a previous report of culturing O. chierchiae in which $4 / 26$ hatchlings reached a maximum age of 67 days before dying (Rodaniche, 1984). This differs from published accounts of culturing other octopus species, in which mortality rates are steady over the entire life cycle (Hanlon and Forsythe, 1985). In our care, 14-15\% of individuals in first- and second-generation clutches survived to over 400 days of age (Figure 6). Survival is lower in the third generation compared to first and second generations, although our present study is greatly limited by the COVID-19 pandemic (Figure 6). Typical signs of senescence exhibited by $O$. chierchiae at the end of life include reduced appetite, discoloration, and cessation of breeding (Anderson et al., 2002), but unlike other species of octopus, senescence is decoupled from the first incidence of reproduction (Rodaniche, 1984; Hofmeister et al., 2011). With further optimization of temperature 
or diet, cultured $O$. chierchiae may regularly live for up to two years and remain fertile for the majority of adulthood (Rodaniche, 1984). These results demonstrate that $O$. chierchiae has a comparable, if not longer, lifespan than many other octopus species commonly reared in culture, such as $O$. bimaculoides (1.5 years (Jereb et al., 2014)) and O. maya (300 days (Van Heukelm, 1977)). This would allow for observations and data collection on adult $O$. chierchiae for extensive periods of time while continuing to breed individuals to sustain the ongoing culture.

\subsection{The advantage of iteroparity}

Unlike most cephalopod species (Mangold, 1987; Cortez et al., 1995), O. chierchiae are iteroparous (Rodaniche, 1984; Hofmeister et al., 2011). Results from this study demonstrate that female $O$. chierchiae are capable of laying a clutch of eggs with mean size of 11-35 eggs approximately every 30 to 90 days while males are capable of mating several times without any apparent negative impact to their health. Some females laid multiple clutches of eggs after a single mating event, suggesting that they likely store sperm acquired from the male for an extended period of time. Sperm storage and sperm competition (Wigby and Chapman, 2004) has been previously reported in O. chierchiae (Rodaniche, 1984) and in other cephalopod species (Hanlon et al., 1999; Naud et al., 2005; Wada et al., 2005; Wada et al., 2010, Squires et al., 2015; Naud et al., 2016), although it is possible that sperm quality is reduced over time (Reinhardt, 2007). The rare iteroparous nature of $O$. chierchiae is extremely beneficial for laboratory culture; it affords multiple opportunities to harvest eggs at a distinct developmental stages and stagger age/size classes in culture.

Our data show that using the tasseling behavior (in males) or first incidence of egg-laying (in females) to estimate sexual maturity appeared to be sufficient for the breeding program to produce large numbers of hatchlings. In our study, the mean age at which females laid their first clutch of eggs was 241 days (Table 2). However, anecdotal necropsy observations performed during this study and from Rodaniche (1984) revealed the presence of eggs in females as young as 67 days of age. It is possible females may become sexually mature much earlier but do not lay eggs in the absence of sexually mature males. Based on the results from this study, we estimate that $O$. chierchiae reach sexual maturity at approximately six months of age, although timing of sexual maturation is likely modulated by temperature and diet. Future investigations are needed to determine the earliest laying time for this species and may be achieved by conducting mating trials at a younger age.

\subsection{Applications in research}

As J.Z. Young outlined in his classic work A Model of the Brain, octopuses offer a unique opportunity to discover 'the rules' of how to build complex brain function by comparing solutions across invertebrate and vertebrate nervous systems. Towards this goal, the advances in octopus husbandry we report here make $O$. chierchiae an especially attractive model organism in diverse scientific fields. Their predictable and repetitive reproduction provides a continuous supply of large, transparent eggs that permit access to the brain and other tissues using modern imaging techniques, such as calcium imaging, computed micro-tomography (micro-CT; Kerbl et al., 2013), ultrasound (Margheri et al., 2011), and magnetic resonance imaging (MRI; Tramacere et al., 2012; Jiang et al., 2014). This makes them an excellent candidate for the study of embryological development across different developmental stages, genetic lineages, and experimental groups. 
The large number of embryos produced by $O$. chierchiae make them an excellent octopus candidate for pioneering CRISPR-Cas9 gene-editing technology, which has been recently demonstrated in squid embryos (Crawford et al., 2020).

A steady supply of direct developing hatchlings provides many advantages to developmental, neurobiological, and behavioral study. Hatchlings exhibit many features of adults, such as hunting, which involves exquisite control of the arms and suckers. Since fluid forces vary across an animal's size, strategies for controlling the flexible arms may change as the animal grows. A colony of $O$. chierchiae provides an opportunity to closely investigate the development and control of the chemotactile system of the arms across the entire lifespan, which has many applications in engineering and robotics. Octopuses also possess a camera-like eye and exhibit a range of visual behaviors, including hunting, predator evasion, navigation, and camouflage (Hanlon and Messenger, 2018). However, their brain organization is dramatically different from other highly visual animals such as vertebrates and insects, and little is known about the neural circuits that process visual information within the octopus brain. Standardized model species, particularly with genetic access, have played a key role in mechanistic studies of visual processing in other species, such as flies, zebrafish, and mouse (Huberman and Niell, 2011; Wernet, Huberman, Desplan 2014; Sanes and Zipursky 2010; Bollmann 2019), and the characteristics of $O$. chierchiae may allow it to serve this role for the unique visual system of cephalopods.

Iteroparity itself is interesting to study because it sets $O$. chierchiae apart from most other octopus species. In semelparous octopuses, reproduction triggers the signaling of the optic glands, the octopus analog of the vertebrate pituitary gland (Wang and Ragsdale 2018, Wells and Wells, 1969). The optic gland signaling systems are responsible for post-mating behavioral changes, including maternal behaviors and death, and have recently been characterized in O. bimaculoides for the first time (Wang and Ragsdale 2018). How the optic glands control reproduction in an iteroparous species is entirely unexplored. A lab-cultured colony of $O$. chierchiae would lay the foundation for investigating the interplay between reproduction and control of lifespan between iteroparous and semelparous octopus species, and accelerate the study of octopus reproductive neuroendocrinology, senescence, and aging.

Furthermore, O. chierchiae is closely related to the Larger Pacific Striped Octopus (LPSO), the only known social species of octopus (Caldwell et al., 2015). The LPSO is known to display unique behaviors such as beak-to-beak mating and mating pairs sharing a den (Caldwell et al., 2015). Importantly, some of the earliest insights into the brain mechanisms underlying social behaviors came from another such pair of asocial/social vertebrate sister species (montane and prairie voles) (Donaldson and Young, 2008). Unlike O. chierchiae, however, the LPSO is a small egg species and hatchlings undergo indirect development (Jereb et al., 2014; Caldwell et al., 2015). The existence of another comparator pair in invertebrates presents an enticing opportunity to test evolutionary hypotheses with the ultimate goal of discovering universal synaptic and circuit motifs that govern sociality across species.

There are still several challenges facing $O$. chierchiae culture. In addition to the careful attention to system design, feeding, and enclosure maintenance required to reduce mortality during the sensitive hatchling phase, our results suggest that the third generation began to 
610 experience the first signs of inbreeding depression (Charlesworth and Charlesworth, 1987). 611 Although data from only one third-generation clutch was available, signs that point towards 612 inbreeding depression in the third generation include: 1) significantly reduced survivorship, 613 particularly in the first week of life (Figure 6), despite improved culture techniques and decreased 614 mortality due to culture-related causes (Table 3); and 2) the birth of a 16-armed octopus, likely 615 due to genetic mutations from the small gene pool. Given that our study began with only seven 616 wild-collected individuals, this observation is not surprising. These findings emphasize the need 617 to periodically supplement the population with new genetics via wild-collected octopuses. 618 Decreased fertility in later generations of laboratory culture has been demonstrated in several 619 cephalopod species including the common cuttlefish, S. officinalis (Forsythe et al., 1994), the 620 flamboyant cuttlefish, Metasepia pfefferi (Grasse, 2014), and the bigfin reef squid, Sepioteuthis 621 lessoniana (Walsh et al., 2002). More research on inbreeding depression and fecundity in $O$. 622 chierchiae is required to help identify genetic bottlenecks and modify protocols to optimize 623 breeding efficiency. Reduced survivorship observed in the third-generation clutch may also have 624 been due to seasonal changes of water parameters of the incoming water source in open seawater 625 systems, seasonal hormonal changes correlated to a breeding season, chemicals released by egg626 laying females affecting the development of other eggs on the same system, or other unknown factors. Additional studies should explore these possibilities in order to understand $O$. chierchiae 628 behavior, breeding, and biology. Due to the elusiveness of $O$. chierchiae in nature, researchers 629 have been unable to study them in the ocean and little is known about their natural history in the 630 wild. Future studies that investigate their distribution patterns, preferred habitats, natural diets, and 631 typical reproductive behaviors in the wild will greatly improve laboratory husbandry practices.

\subsection{Conclusion}

O. chierchiae is an ideal model organism due to its small size, iteroparity, and predictable reproduction, and direct developing hatchlings. Various aspects of octopus behavior and biology make laboratory culture challenging: a rapid metabolism that emphasizes the need for optimal water quality and frequent feeds, an affinity to escape enclosures, cannibalistic tendencies, and the requirement for large amounts of physical space. We have developed a culture program for $O$. chierchiae that optimizes reproductive success and survivorship to address the various challenges of octopus aquaculture. Starting with seven wild-collected individuals, we successfully reared $O$. chierchiae up to the third generation in large enough numbers to maintain a population spanning all life stages for over two years. More research in both the laboratory and the wild is needed to investigate the effects of temperature and diet on growth rates, reproduction, and lifespan, to identify the precise timing and cues for the onset of sexual maturity in this species, and to study mating behaviors in order to optimize breeding programs and maximize reproductive output. In the long term, periodically supplementing an $O$. chierchiae culture with new genetic pools from wild-collected octopuses likely would reduce inbreeding-related defects and mortality, which will be important for maintaining a healthy, sustainable culture of $O$. chierchiae. 


\section{Ethical note}

649 In the USA, cephalopods are not included in federal regulations that govern the use of animals 650 in research laboratories, thus no protocol or approval number was required for this study. 651 However, the Marine Biological Laboratory voluntarily upholds a Cephalopod Care Policy and 652 the care of the animals in this study adhered to that policy. All animal care and handling followed 653 methods established by the regulations of the Directive 2010/63/EU for cephalopods (Fiorito et 654 al., 2015a; Smith et al., 2013; Sykes et al., 2012) and institutional standards for cephalopod care.

\section{Author contribution statement}

656 AGG, AD, TS, and BG contributed to the conception and design of the study. AGG, AD, and

657 ZYW analyzed the data and wrote the manuscript. All authors contributed to manuscript revision, 658 read, and approved the submitted version.

\section{Conflicts of interest}

660 The authors declare that the research was conducted in the absence of any commercial or financial 661 relationships that could be construed as a potential conflict of interest.

\section{$662 \quad$ Funding}

663 The cephalopod program at the Marine Biological Laboratory (MBL) was supported by NSF 6641827509 and NSF 1723141 grants. CMN received funding from HFSP RGP0042. ZYW was 665 supported by funds from the Whitman Center at the MBL. DHG and DMS received funding and 666 research support from the University of Washington Friday Harbor Laboratories.

\section{Acknowledgements}

668 We acknowledge the pioneering culture efforts of Rich Ross, Danielle Dallis, Travis Snyder, 669 Benjamin Liu, Anna Ramji, Leo Song, and Saumitra Kelkar; Mathew Everett, Peter Kilian, and 670 all former interns in the Cephalopod Program at the Marine Biological Laboratory (MBL) for 671 assistance with data collection and ongoing O. chierchiae culture; and Philip Swiny, Carlos 672 Carstens, Juan-chi, Vanessa Grasse, and William Wcislo (Smithsonian Tropical Research 673 Institute) for support with field collection investigations. We thank Roger Hanlon, Jonathon Stone, 674 and David Welch for providing feedback on earlier versions of the manuscript, Tim Briggs for his 675 exceptional photographs of the octopuses, and Caroline Albertin for research support. We are 676 grateful for Joshua Rosenthal's support of the MBL's cephalopod culture efforts, and for John 677 Sigel and Sally Reid's support of the Northeastern University Co-op Internship Program at the 678 MBL. 


\section{References}

680 Anderson, R. C., Wood, J. B., and Byrne, R. A. (2002). Octopus senescence: the beginning of the 681 end. Journal of Applied Animal Welfare Science. 5(4), 275-283. doi:

682 10.1207/S15327604JAWS0504_02

683 Baeza-Rojano, E., Domingues, P., Guerra-García, J. M., Capella, S., Noreña-Barroso, E., 684 Caamal-Monsreal, C., et al. (2013). Marine gammarids (Crustacea: Amphipoda): a new live prey 685 to culture Octopus maya hatchlings. Aquaculture Research. 44(10), 1602-1612. doi:

$686 \quad$ 10.1111/j.1365-2109.2012.03169.x

687 Boletzky S.V., and Hanlon R.T. (1983). A review of the laboratory maintenance, rearing and 688 culture of cephalopod molluscs. Memoirs of the National Museum of Victoria.44, 147-187.

689 Boucher-Rodoni, R., and Mangold, K. (1995). Ammonia production in cephalopods, 690 physiological and evolutionary aspects. Marine and Freshwater Behaviour and Physiology. 691 25(1-3), 53-60. doi: 10.1080/10236249409378907

692 Caldwell, R. L., Ross, R., Rodaniche, A., and Huffard, C. L. (2015). Behavior and body

693 patterns of the larger Pacific striped octopus. PloS ONE. 10(8), e0134152. doi:

694 10.1371/journal.pone.0134152

695 Charlesworth, D., and Charlesworth, B. (1987). Inbreeding depression and its evolutionary 696 consequences. Annual Review of Ecology and Systematics. 18(1), 237-268. doi:

697 10.1146/annurev.es.18.110187.001321

698 Cortez, T., Castro, B. G., and Guerra, A. (1995). Reproduction and condition of female Octopus 699 mimus (Mollusca: Cephalopoda). Marine Biology. 123(3), 505-510. doi: 10.1007/BF00349229

700 Crawford, K., Quiroz, J. F. D., Koenig, K. M., Ahuja, N., Albertin, C. B., and Rosenthal, J. J. 701 (2020). Highly efficient knockout of a squid pigmentation gene. Current Biology. 30(17), 3484702 3490. doi: 10.1016/j.cub.2020.06.099

703 DeRusha, R. H., Forsythe, J. W., and Hanlon, R. T. (1987). Laboratory growth, reproduction and 704 life span of the Pacific pygmy octopus, Octopus digueti. Pacific Science. 41(1-4), 104-121.

705 Di Cosmo, A., Bertapelle, C., Porcellini, A., and Polese, G. (2018). Magnitude assessment of 706 adult neurogenesis in the Octopus vulgaris brain using a flow cytometry-based

707 technique. Frontiers in Physiology. 9, 1050. doi: 10.3389/fphys.2018.01050

708 Di Cristo, C. (2013). Nervous control of reproduction in Octopus vulgaris: a new

709 model. Invertebrate Neuroscience. 13(1), 27-34. doi: 10.1007/s10158-013-0149-X

710 Domingues, P. M., López, N., Muñoz, J. A., Maldonado, T., Gaxiola, G., and Rosas, C. (2007). 711 Effects of a dry pelleted diet on growth and survival of the Yucatan octopus, Octopus maya.

712 Aquaculture Nutrition. 13(4), 273-280. doi: 10.1111/j.1365-2095.2007.00474.x 
Donaldson, Z. R., and Young, L. J. (2008). Oxytocin, vasopressin, and the neurogenetics of sociality. Science. 322(5903), 900-904. doi: 10.1126/science.1158668

715 Edsinger, E., and Dölen, G. (2018). A conserved role for serotonergic neurotransmission in mediating social behavior in octopus. Current Biology. 28(19), 3136-3142. doi:

$717 \quad$ 10.1016/j.cub.2018.07.061

718 Fiorito, G., Affuso, A., Basil, J., Cole, A., de Girolamo, P., D’angelo, L., et al. (2015). Guidelines for the Care and Welfare of Cephalopods in Research -A consensus based on an initiative by CephRes, FELASA and the Boyd Group. Laboratory Animals. 49, 1-90. doi: 10.1177/0023677215580006

722 Forsythe, J. W., and Hanlon, R. T. (1988). Effect of temperature on laboratory growth, 723 reproduction and life span of Octopus bimaculoides. Marine Biology. 98(3), 369-379. doi: $724 \underline{10.1007 / \mathrm{BF} 00391113}$

725 Forsythe, J. W., and Van Heukelem, W. F. (1987). "Growth," in Cephalopod Life Cycles, 726 Volume II: Comparative Reviews, ed. P.R. Boyle (London: Academic Press), 135-156.

727 Forsythe, J. W., DeRusha, R. H., and Hanlon, R. T. (1994). Growth, reproduction and life 728 span of Sepia officinalis (Cephalopoda: Mollusca) cultured through seven consecutive 729 generations. Journal of Zoology. 233(2), 175-192. doi: 10.1111/j.1469-7998.1994.tb08582.x

730 Forsythe, J., Lee, P., Walsh, L., and Clark, T. (2002). The effects of crowding on growth of the 731 European cuttlefish, Sepia officinalis Linnaeus, 1758 reared at two temperatures. Journal of 732 Experimental Marine Biology and Ecology. 269(2), 173-185. doi: 10.1016/S0022-

$733 \quad \underline{0981(02) 00006-0}$

734 García, B. G., and Valverde, J. C. (2006). Optimal proportions of crabs and fish in diet for 735 common octopus (Octopus vulgaris) ongrowing. Aquaculture. 253(1-4), 502-511. doi:

$736 \quad 10.1016 /$ j.aquaculture.2005.04.055

737 Garrido, D., Martín, M. V., Rodríguez, C., Iglesias, J., Navarro, J. C., Estévez, A., et al. (2018). 738 Meta-analysis approach to the effects of live prey on the growth of Octopus vulgaris paralarvae 739 under culture conditions. Reviews in Aquaculture. 10(1), 3-14. doi: 10.1111/raq.12142

740 Geffeney, S. L., Williams, B. L., Rosenthal, J. J., Birk, M. A., Felkins, J., Wisell, C. M., et al. 741 (2019). Convergent and parallel evolution in a voltage-gated sodium channel underlies TTX742 resistance in the greater blue-ringed octopus: Hapalochlaena lunulata. Toxicon. 170, 77-84. doi:

$743 \quad 10.1016 /$ j.toxicon.2019.09.013

744 Gutfreund, Y., Flash, T., Yarom, Y., Fiorito, G., Segev, I., and Hochner, B. (1996). Organization 745 of octopus arm movements: a model system for studying the control of flexible arms. Journal of 746 Neuroscience. 16(22), 7297-7307. doi: 10.1523/JNEUROSCI.16-22-07297.1996

747 Grasse, B., Aquarist, I. I., Aquarium, M. B., and Row, C. (2014). The biological 748 characteristics, life cycle, and system design for the flamboyant and paintpot cuttlefish, 749 Metasepia sp., cultured through multiple generations. Drum and Croaker. 45, 58-71. 
Grigoriou, P., and Richardson, C. A. (2008). The effect of ration size, temperature and body weight on specific dynamic action of the common cuttlefish Sepia officinalis. Marine Biology. 154(6), 1085-1095. doi: 10.1007/s00227-008-1002-3

753 Hanlon, R. T., and Forsythe, J. W. (1985). Advances in the laboratory culture of octopuses

754 for biomedical research. Laboratory Animal Science. 35(1), 33-40.

755 Hanlon, R. T. (1987). "Mariculture," in Cephalopod Life Cycles, Volume II: Comparative 756 Reviews, ed. P.R. Boyle (London: Academic Press), 291-305.

757 Hanlon, R. T., Ament, S. A., and Gabr, H. (1999). Behavioral aspects of sperm competition in 758 cuttlefish, Sepia officinalis (Sepioidea: Cephalopoda). Marine Biology. 134(4), 719-728. doi:

$759 \underline{10.1007 / \mathrm{s} 002270050588}$

760 Hanlon, R. T., Chiao, C. C. C., Mathger, L. M., Buresch, K. C., Barbosa, A., Allen, J. J., et al. (2011). "Rapid adaptive camouflage in cephalopods," in Animal Camouflage, ed. S.

762 Merilaita (Cambridge, UK: University Press), 145-163.

763 Hanlon, R., and Messenger, J. (2018). Cephalopod Behaviour (2nd ed.). Cambridge:

764 Cambridge University Press. doi: $10.1017 / 9780511843600$

Hochner, B., Shomrat, T., and Fiorito, G. (2006). The octopus: a model for a comparative analysis of the evolution of learning and memory mechanisms. The Biological Bulletin. 210(3), 308-317. doi: $\underline{10.2307 / 4134567}$

768 Hofmeister, J. K., Alupay, J. S., Riss, R., and Caldwell, R. L. (2011). Observations on mating behavior and development in the lesser Pacific striped octopus, Octopus chierchiae (Jatta, 1889). Society for Integrative and Comparative Biology 2011 Annual Meeting. Abstract retrieved from http://www.sicb.org/meetings/2011/schedule/abstractdetails.php3?id=627

772 Huffard, C. L. (2013). Cephalopod neurobiology: an introduction for biologists working in other 773 model systems. Invertebrate Neuroscience. 13(1), 11-18. doi: 10.1007/s10158-013-0147-z

774 Ibánez, C. M., and Keyl, F. (2010). Cannibalism in cephalopods. Reviews in Fish Biology and 775 Fisheries. 20(1), 123-136. doi: 10.1007/s11160-009-9129-y

776 Iglesias, J., Otero, J. J., Moxica, C., Fuentes, L., and Sánchez, F. J. (2004). The completed life 777 cycle of the octopus (Octopus vulgaris, Cuvier) under culture conditions: paralarval rearing 778 using Artemia and zoeae, and first data on juvenile growth up to 8 months of age. Aquaculture 779 International. 12(4-5), 481-487. doi: 10.1023/B:AQUI.0000042142.88449.bc

780 Iglesias, J., Sánchez, F. J., Bersano, J. G. F., Carrasco, J. F., Dhont, J., Fuentes, L., et al. (2007). 781 Rearing of Octopus vulgaris paralarvae: present status, bottlenecks and trends. Aquaculture. 782 266(1-4), 1-15. doi: 10.1016/j.aquaculture.2007.02.019

783 Iglesias, J., Sánchez, F. J., Otero, J. J., and Moxica, C. (2000). Culture of octopus (2FWRSXV 784 YXOJDULV, Cuvier): Present knowledge, problems and perspectives. Cahiers Options

785 Méditerranéennes. (47), 313-321. 
Itami, K., Izawa, Y., Maeda, S., and Nakai, K. (1963). Notes on the laboratory culture of the octopus larvae. Bulletin of the Japanese Society of Scientific Fisheries. 29(6), 514-519.

Jereb, P., Roper, C. F. E., Norman, M. D., and Finn, J. K. (2014). Cephalopods of the world. An annotated and illustrated catalogue of cephalopod species known to date. Volume 3: Octopods and Vampire Squids. FAO Species Catalogue for Fishery Purposes No. 4, Vol. 3.

791 Jiang, X., Lu, H., Shigeno, S., Tan, L. H., Yang, Y., Ragsdale, C. W., and Gao, J. H. (2014).

792 Octopus visual system: A functional MRI model for detecting neuronal electric currents without 793 a blood oxygen level dependent confound. Magnetic Resonance in Medicine. 72(5), 1311-1319.

794 doi: $10.1002 / \mathrm{mrm} .25051$

795

796

797

798

799

800

801

802

803

804

805

806

807

808

809

810

811

812

813

814

815

816

817

818 Mangold, K. (1987). "Reproduction," in Cephalopod Life Cycles, Volume II: Comparative 819

Juárez, O. E., López-Galindo, L., Pérez-Carrasco, L., Lago-Lestón, A., Rosas, C., Di Cosmo, A., and Galindo-Sánchez, C. E. (2019). Octopus maya white body show sex-specific transcriptomic profiles during the reproductive phase, with high differentiation in signaling pathways. PloS ONE. 14(5), e0216982. doi: 10.1371/journal.pone.0216982

Kerbl, A., Handschuh, S., Nödl, M. T., Metscher, B., Walzl, M., and Wanninger, A. (2013). Micro-CT in cephalopod research: investigating the internal anatomy of a sepiolid squid using a non-destructive technique with special focus on the ganglionic system. Journal of Experimental Marine Biology and Ecology. 447, 140-148. doi: 10.1016/j.jembe.2013.02.022

Laptikhovsky, V.V. (1998). Differentiation of reproductive strategies within a taxon, as exemplified by octopods. Ruthenica. 8(1), 77-80.

Lee, P. G. (1995). Nutrition of cephalopods: fueling the system. Marine and Freshwater Behaviour and Physiology. 25(1-3), 35-51. doi: 10.1080/10236249409378906

Lee, P. G., Turk, P. E., Forsythe, J. W., and Dimarco, F. P. (1998). Cephalopod culture: physiological, behavioral and environmental requirements. Aquaculture Science. 46(3), 417-422. doi: $\underline{10.11233 / \text { aquaculturesci1953.46.417 }}$

Margheri, L., Ponte, G., Mazzolai, B., Laschi, C., and Fiorito, G. (2011). Non-invasive study of Octopus vulgaris arm morphology using ultrasound. Journal of experimental biology. 214(22), 3727-3731. doi: $\underline{10.1242 / \mathrm{jeb} .057323}$

Maiole, F., Giachero, S., Fossati, S. M., Rocchi, A., and Zullo, L. (2019). mTOR as a Marker of Exercise and Fatigue in Octopus vulgaris Arm. Frontiers in Physiology. 10, 1161. doi: 10.3389/fphys.2019.01161

Mangold, K., and Von Boletzky, S. (1973). New data on reproductive biology and growth of Octopus vulgaris. Marine Biology. 19(1), 7-12. doi: 10.1007/BF00355414

Reviews, ed. P.R. Boyle (London: Academic Press), 157-200. 
Miliou, H., Fintikaki, M., Kountouris, T., and Verriopoulos, G. (2005). Combined effects of temperature and body weight on growth and protein utilization of the common octopus, Octopus vulgaris. Aquaculture. 249(1-4), 245-256. doi: 10.1016/j.aquaculture.2005.03.038

Naud, M. J., Shaw, P. W., Hanlon, R. T., and Havenhand, J. N. (2005). Evidence for biased use of sperm sources in wild female giant cuttlefish (Sepia apama). Proceedings of the Royal Society B: Biological Sciences. 272(1567), 1047-1051. doi: 10.1098/rspb.2004.3031

826 Naud, M. J., Sauer, W. H., McKeown, N. J., and Shaw, P. W. (2016). Multiple mating, paternity and complex fertilisation patterns in the chokka squid Loligo reynaudii. PLoS ONE. 11(2), e0146995. doi: 10.1371/journal.pone.0146995.t001

Navarro, J. C., Monroig, Ó., and Sykes, A. V. (2014). "Nutrition as a key factor for cephalopod aquaculture," in Cephalopod culture, ed. Iglesias J., Fuentes L., and Villanueva R. (Dordrecht, Springer), 77-95. doi: 10.1007/978-94-017-8648-5 5

832 O’Dor, R. K. and Wells, M. J. (1987). "Energy and nutrient flow," in Cephalopod Life Cycles, 833 Volume II: Comparative Reviews, ed. P.R. Boyle (London: Academic Press), 109-133.

834 Oestmann, D. J., Scimeca, J. M., Forsythe, J., Hanlon, R., and Lee, P. (1997). Special considerations for keeping cephalopods in laboratory facilities. Journal of the American Association for Laboratory Animal Science. 36(2), 89-93.

837 Pham, C. K., and Isidro, E. (2009). Growth and mortality of common octopus (Octopus vulgaris) 838 fed a monospecific fish diet. Journal of Shellfish Research. 28(3), 617-623. doi:

$839 \quad \underline{10.2983 / 035.028 .0326}$

840 Prato, E., Portacci, G., and Biandolino, F. (2010). Effect of diet on growth performance, feed efficiency and nutritional composition of Octopus vulgaris. Aquaculture. 309(1-4), 203-211. doi:

$842 \quad 10.1016 /$ j.aquaculture.2010.09.036

843 Reinhardt, K. (2007). Evolutionary consequences of sperm cell aging. The Quarterly review of 844 biology. 82(4), 375-393. doi: $\underline{10.1086 / 522811}$

845 Rocha, F., Guerra, Á., and González, Á. F. (2001). A review of reproductive strategies in 846 cephalopods. Biological Reviews. 76(3), 291-304. doi: 10.1017/S1464793101005681

847 Rodaniche, A. F. (1984). Iteroparity in the lesser Pacific striped octopus Octopus chierchiae 848 (Jatta, 1889). Bulletin of Marine Science. 35(1), 99-104.

849 Roper, C. F., and Mangold, K. M. (1991). Octopus schultzei (Hoyle, 1910): a redescription with 850 designation of Aphrodoctopus new genus (Cephalopoda; Octopodinae). Bulletin of Marine 851 Science, 49(1-2), 57-72.

852 Rosas, C., Cuzon, G., Pascual, C., Gaxiola, G., Chay, D., López, N., et al. (2007). Energy 853 balance of Octopus maya fed crab or an artificial diet. Marine Biology. 152(2), 371-381. doi: 
Rosas, C., Valero, A., Caamal-Monsreal, C., Uriarte, I., Farias, A., Gallardo, P., et al. (2013). Effects of dietary protein sources on growth, survival and digestive capacity of Octopus maya juveniles (Mollusca: Cephalopoda). Aquaculture Research.44(7), 1029-1044. doi: 10.1111/j.1365-2109.2012.03107.x exert self-control in a delay of gratification task. Proceedings of the Royal Society B. 288(1946), 20203161. doi: $10.1098 / \mathrm{rspb} .2020 .3161$

862 Shigeno, S., and Ragsdale, C. W. (2015). The gyri of the octopus vertical lobe have distinct neurochemical identities. Journal of Comparative Neurology. 523(9), 1297-1317. doi: 10.1002/cne.23755

Sinn, D. L., Perrin, N. A., Mather, J. A., and Anderson, R. C. (2001). Early temperamental traits in an octopus (Octopus bimaculoides). Journal of Comparative Psychology. 115(4), 351. doi: $\underline{10.1037 / 0735-7036.115 .4 .351}$

Smith, J. A., Andrews, P. L. R., Hawkins, P., Louhimies, S., Ponte, G., and Dickel, L. (2013). Cephalopod research and EU Directive 2010/63/EU: Requirements, impacts and ethical review. Journal of Experimental Marine Biology and Ecology. 447, 31-45. doi:

$871 \quad$ 10.1016/j.jembe.2013.02.009

872 Squires, Z. E., Wong, B. B., Norman, M. D., and Stuart-Fox, D. (2015). Last male sperm 873 precedence in a polygamous squid. Biological Journal of the Linnean Society. 116(2), 277-287. 874 doi: $\underline{10.1111 / \text { bij.12590 }}$

875 Stubbs, A. L., and Stubbs, C. W. (2016). Spectral discrimination in color blind animals via chromatic aberration and pupil shape. Proceedings of the National Academy of Sciences. 113(29), 8206-8211. doi: 10.1073/pnas.1524578113 arms. Nature. 433(7026), 595-596. doi: 10.1038/433595a on animal welfare: A review on the existing scientific knowledge and implications in cephalopod aquaculture research. Reviews in Aquaculture. 4(3), 142-162. doi: 10.1111/j.1753$\underline{5131.2012 .01070 .}$.

Tramacere, F., Beccai, L., Mattioli, F., Sinibaldi, E., and Mazzolai, B. (2012). Artificial adhesion mechanisms inspired by octopus suckers. In 2012 IEEE International Conference on Robotics and Automation. IEEE. 3846-3851. doi: 10.1109/ICRA.2012.6225058 mechanical properties of Octopus vulgaris suckers. Journal of The Royal Society Interface. 
Van Heukelem, W. F. (1977). Laboratory maintenance, breeding, rearing, and biomedical research potential of the Yucatan octopus (Octopus maya). Laboratory Animal Science. 27(5 Pt

894 2), 852-859.

Vaz-Pires, P., Seixas, P., and Barbosa, A. (2004). Aquaculture potential of the common octopus (Octopus vulgaris Cuvier, 1797): a review. Aquaculture . 238(1-4), 221-238. doi: 10.1016/j.aquaculture.2004.05.018

Vidal, E. A., DiMarco, F. P., Wormuth, J. H., and Lee, P. G. (2002). Influence of temperature and food availability on survival, growth and yolk utilization in hatchling squid. Bulletin of Marine Science. 71(2), 915-931.

Vidal, E. A., and von Boletzky, S. (2014). "Loligo vulgaris and Doryteuthis opalescens,"

902 in Cephalopod culture, ed. Iglesias J., Fuentes L., and Villanueva R. (Dordrecht, Springer), 271-

903 313. doi: $10.1007 / 978-94-017-8648-5 \quad 16$

904 Vidal, E.A., Villanueva, R., Andrade, J.P., Gleadall, I.G., Iglesias, J., Koueta, N., et al. (2014).

905 Cephalopod culture: current status of main biological models and research priorities. Advances in

906 Marine Biology. 67, 1-98. doi: 10.1016/B978-0-12-800287-2.00001-9

907 Voss, G. L. (1968). Biological Investigations of the Deep Sea. 39. Octopods from the R/V

908 Pillsbury Southwestern Caribbean Cruise, 1966, with a description of a new species, Octopus

909 zonatus. Bulletin of Marine Science. 18(3), 645-659.

910 Voss, G. L. (1971). Biological Results of the University of Miami Deep-Sea Expeditions. 76.

911 Cephalopods Collected by the R/V John Elliott Pillsbury in the Gulf of Panama in 1967. Bulletin

912 of Marine Science. 21(1), 1-34.

913 Wada, T., Takegaki, T., Mori, T., and Natsukari, Y. (2005). Sperm displacement behavior of the 914 cuttlefish Sepia esculenta (Cephalopoda: Sepiidae). Journal of ethology. 23(2), 85-92. doi:

$915 \quad \underline{10.1007 / \mathrm{s} 10164-005-0146-6}$

916 Wada, T., Takegaki, T., Mori, T., and Natsukari, Y. (2010). Sperm removal, ejaculation and their 917 behavioural interaction in male cuttlefish in response to female mating history. Animal

918 Behaviour. 79(3), 613-619. doi: 10.1016/j.anbehav.2009.12.004

919 Walsh, L. S., Turk, P. E., Forsythe, J. W., and Lee, P. G. (2002). Mariculture of the Loliginid 920 squid Sepioteuthis lessoniana through seven successive generations. Aquaculture. 212(1-4), 245921 262. doi: 10.1016/S0044-8486(02)00126-6

922 Wang, Z. Y., and Ragsdale, C. W. (2018). Multiple optic gland signaling pathways implicated in 923 octopus maternal behaviors and death. Journal of Experimental Biology. 221(19). doi:

$924 \quad 10.1242 /$ jeb.185751

925 Wells, M. J., and Wells, J. (1969). Pituitary analogue in the octopus. Nature. 222(5190), 293 -

926 294. doi: $10.1038 / 222293 \mathrm{a0}$ 
927 Wells, M.J. (1978). "An outline of the anatomy," in Octopus: Physiology and Behaviour of an 928 Advanced Invertebrate. (Dordrecht, Springer), 12-13. doi: 10.1007/978-94-017-2468-5 2

929 Wigby, S., and Chapman, T. (2004). Sperm competition. Current Biology. 14(3), R100-R103. 930 doi: $10.1016 /$ j.cub.2004.01.013

931 Wood, J. B., and Anderson, R. C. (2004). Interspecific evaluation of octopus escape behavior. 932 Journal of Applied Animal Welfare Science. 7(2), 95-106. doi: 10.1207/s15327604jaws0702 2

933 Young, J. Z. (1971). The Anatomy of the Nervous System of Octopus vulgaris. Oxford: 934 Clarendon Press. 
936 Table 1. Mean age of $\boldsymbol{O}$. chierchiae when moved to larger enclosures. Octopuses were held in 937 11/4-inch PVC enclosures from birth until moved to juvenile enclosures. Juvenile enclosures were 938 4-inch PVC enclosures (see Section 2.3). Adult enclosures were 2.84 L plastic aquaria (see Section 939 2.3). Octopuses were moved to juvenile and adult enclosures when they outgrew the size 940 constraints of their given enclosure (i.e., the distance between opposite arm tips reached 941 approximately half of the enclosure diameter). $n=$ number of individuals; SEM=standard error of 942 the mean.

\begin{tabular}{lllll}
\hline Enclosure size & $\boldsymbol{n}$ & Mean age (days) & SEM & Range \\
\hline Juvenile (4-inch PVC enclosure) & 162 & 94 & 1.77 & $64-187$ \\
\hline Adult (2.84L aquaria) & 83 & 211 & 3.34 & $144-292$ \\
\hline
\end{tabular}

Table 2. Mean age of $\boldsymbol{O}$. chierchiae at estimated sexual maturity. The tasseling behaviour was used to estimate sexual maturity in males. The first incidence of laying a clutch of eggs was used to estimate sexual maturity in females. $n=$ number of individuals; SEM=standard error of the mean.

\begin{tabular}{lllll}
\hline Sexual maturity & $\boldsymbol{n}$ & Mean age (days) & SEM & Range \\
\hline Males (tasseling) & 10 & 176 & 8.60 & $136-208$ \\
\hline Females (first clutch laid) & 31 & 241 & 4.59 & $196-299$ \\
\hline
\end{tabular}

Table 3. $O$. chierchiae mortalities by generation classified by cause of death. Natural deaths were defined as any mortality not caused by direct human interference or error and included death due to old age or any unknown health-related issues. Other non-natural causes of death included being crushed under enclosure lids (only occurred with the smallest hatchlings), escape from enclosures, euthanasia with $2-5 \%$ ethanol after observing signs of senescence or compromised health, use in experimental diets or enclosures, stress caused by external factors (such as poor water quality), system problems, or other unknown causes (i.e., cause of death was not recorded at time of mortality). F1=first generation; F2=second generation; F3=third generation; $n=$ number of mortalities.

\begin{tabular}{lccc}
\hline & \multicolumn{3}{c}{ Percent $(n)$} \\
\hline Cause of mortality & $\boldsymbol{F 1}$ & $\boldsymbol{F 2}$ & $\boldsymbol{F 3}$ \\
\hline Natural death & $\mathbf{5 4 . 9}(173)$ & $\mathbf{7 6 . 6}(281)$ & $\mathbf{1 0 0 . 0}(22)$ \\
\hline Crushing & $\mathbf{7 . 0}(22)$ & $\mathbf{3 . 0}(11)$ & $0(0)$ \\
\hline Desiccation & $\mathbf{2 5 . 0}(79)$ & $\mathbf{1 . 3}(5)$ & $0(0)$ \\
\hline Escaped & $\mathbf{1 . 3}(4)$ & $\mathbf{4 . 9}(18)$ & $0(0)$ \\
Euthanasia & $\mathbf{1 . 3}(4)$ & $\mathbf{1 . 9}(7)$ & $0(0)$ \\
\hline Experimental diet/enclosure & $\mathbf{3 . 5}(11)$ & $\mathbf{6 . 8}(25)$ & $0(0)$ \\
Stress & $\mathbf{1 . 3}(4)$ & $\mathbf{0 . 3}(1)$ & $0(0)$ \\
System problems & $\mathbf{1 . 9}(6)$ & $\mathbf{0 . 3}(1)$ & $0(0)$ \\
Unknown & $\mathbf{3 . 8}(12)$ & $\mathbf{4 . 9}(18)$ & $0(0)$ \\
\hline Total mortalities & $\mathbf{1 0 0}(315)$ & $\mathbf{1 0 0}(367)$ & $\mathbf{1 0 0}(22)$ \\
\hline
\end{tabular}

